\title{
ANR Corpus architecturae religiosae europeae [CARE], saec. IV-X
}

\section{Christian Sapin et Pascale Chevalier}

\section{(2) OpenEdition}

1 Journals

\section{Édition électronique}

URL : https://journals.openedition.org/cem/11298

DOI : 10.4000/cem. 11298

ISSN : 1954-3093

Éditeur

Centre d'études médiévales Saint-Germain d'Auxerre

\section{Édition imprimée}

Date de publication : 15 août 2009

Pagination : 81

ISSN : 1623-5770

\section{Référence électronique}

Christian Sapin et Pascale Chevalier, «ANR Corpus architecturae religiosae europeae [CARE], saec. IVX», Bulletin du centre d'études médiévales d'Auxerre / BUCEMA [En ligne], 13 | 2009, mis en ligne le 16 septembre 2009, consulté le 22 septembre 2022. URL : http://journals.openedition.org/cem/11298 ; DOI : https://doi.org/10.4000/cem. 11298

Ce document a été généré automatiquement le 22 septembre 2022.

\section{cc) (i) (ㅇ)}

Creative Commons - Attribution - Pas d'Utilisation Commerciale - Partage dans les Mêmes Conditions 4.0 International - CC BY-NC-SA 4.0

https://creativecommons.org/licenses/by-nc-sa/4.0/ 


\title{
ANR Corpus architecturae religiosae europeae [CARE], saec. IV-X
}

\author{
Christian Sapin et Pascale Chevalier
}

1 Le projet ANR sur le Corpus des monuments religieux antérieurs à l'an Mil (CARE - IV-X saec.) est désormais dans sa phase active. Rappelons qu'il s'agit de recenser tous les édifices religieux entre le $\mathrm{IV}^{e}$ et le début du $\mathrm{XI}^{\mathrm{e}}$ siècle afin de s'inscrire dans un programme européen en cours dans plusieurs pays (Italie, Espagne, Croatie, Europe centrale...) ${ }^{1}$.

2 Plusieurs réunions ont eu lieu en 2008 et début 2009, à Bordeaux, Toulouse, Lyon, Poitiers, Aix-en-Provence... et bientôt à Montpellier ou Caen, et d'autres dates ont été retenues en 2009-2010 pour l'avancement du corpus et la constitution d'équipes par région. Il apparaît d'ores et déjà que certaines régions peuvent s'investir plus que d'autres pour des raisons diverses, souvent de disponibilité des membres; aussi, certains choix devront être faits pour parvenir à finaliser plusieurs régions du Corpus dans une première vague de publication en 2011. D'autres régions s'engageront dans quelques mois - et sans attendre une publication papier - dans la saisie de notices pour alimenter la base de données en cours d'expérimentation. L'aide des Régions (collectivités territoriales) sera nécessaire pour certains dossiers complexes et le financement de programmes complémentaires de relevés, dessins ou saisie.

Il existe désormais une version papier et bientôt une version informatique de la fiche de saisie, selon les normes retenues et adaptées depuis les premières rencontres européennes. La plupart des édifices n'ont souvent à être renseignés que pour quelques rubriques ou champs; c'est l'ordre choisi des intitulés qui est important pour permettre les comparaisons et, plus tard, les requêtes informatiques. Nous travaillons à la mise en place, entre avril et octobre, de cette base de données sous un principe simplifié et innovant de type Wiki qui permettra de remplir directement en ligne les fiches informatiques sur chaque monument. La saisie prendra inévitablement du temps mais le système Wiki devrait rendre plus facile la transposition des données. Ce projet 
de corpus en ligne sera dans quelques années une chance pour la recherche, autant en France que pour les pays étrangers qui s'appliquent au même exercice.

\section{NOTES}

1. Cf. Bulletin du Centre d'études médiévales d'Auxerre, 12 (2008), p. 93-96 [http://cem.revues.org/document6132.html]. 